\title{
Challenging the Stigma of Schizophrenia
}

Schizophrenia and related disorders are a group of severe mental disorders that first appear in late adolescence or early adulthood. ${ }^{1}$ In nearly every society, schizophrenia is highly stigmatized. Prejudice and discrimination related to schizophrenia lead to poor treatment compliance, increased social isolation, difficulties in finding housing, education and employment and increased probability of alcohol and drug abuse. These consequences contribute to the disability produced by the disorder and establish a vicious circle of disadvantage increasing the burden on patients and their families. ${ }^{2}$

Stigma associated with schizophrenia also extends to healthcare providers. Psychiatrists and mental health workers are often marginalized in the health care system; mental health services receive less investment compared to other medical services; treatment settings are understaffed and therefore perform poorer services, perpetuating the image of being inefficient. Unfortunately, health providers including psychiatrists also have negative attitudes to schizophrenia and can contribute to stigma..$^{3,4}$

The Brazilian Mental Health System was mostly hospitalbased until mid1980's. Since then, there has been a 36\% reduction in the number of psychiatric beds (for the period of 1984-1996) and the development of community-based services, which are slowly increasing. Still, poor access to health care, lack of adequate extra-hospital services and facilities, poor training of mental health professionals, neglect of the human rights of the mentally ill, misdiagnosed and untreated patients, are problems not yet adequately addressed by Health Policies and Services. ${ }^{5}$

There is an estimated 1.17 million persons with schizophrenia in Brazil. For many, prejudice and discrimination may constitute an everyday experience, present in difficulties and obstacles posed by the lack of adequate treatment settings, access to information and legal/social support. Although local data concerning these issues are scarce, indicatives of the major barrier posed by poor access to treatment and information were brought about by a study carried to estimate the direct medical cost of schizophrenia for the public sector in the state of São Paulo. The study, focusing a one-year period (1998), detected that approximately $70 \%$ of the estimated patients were not in regular treatment, and outpatient services were receiving only $11 \%$ of the resources destined to treat the disorder. ${ }^{6}$
There is still scarcity of local data concerning these issues; nevertheless, indicatives of the major barrier posed by poor access to treatment and information were brought about by a study carried to estimate the direct medical cost of schizophrenia for the public sector in the state of São Paulo during a one-year period (1998), detecting that approximately $70 \%$ of the patients were not in regular treatment, and outpatient services were receiving only $11 \%$ of the resources destined to treat the disorder. ${ }^{6}$

Brazilian kinship structure is strongly tied to family relationships. When one member in the family becomes severely ill, the illness is likely to turn into a family matter. However, professionals in mental health services seldom hear the relatives of patients. And even though they are seen as important to the patient's treatment, few psychiatric services offer family interventions. Families internalize stigma and suffer with shame, guilt, anger, and distrust of others - doctors and mental health services included.

Combating stigma and discrimination must be a longstanding effort embedded in a network of collaborating agencies. Toward this end and within this framework, The World Psychiatric Association (WPA) initiated in 1996 a program to fight stigma and discrimination because of schizophrenia, currently undertaken by 20 countries around the world. The Brazilian site of the program, supported by the Brazilian Psychiatric Association (ABP), launched in 2001 a program plan named "Projeto S.O.eSq" (Serviço de Orientação à Esquizofrenia), comprising the following key strategies:

- Foster empowerment of patients and family members, supporting active involvement in all actions and developing capacity and leadership to enable advocacy.

- Have representatives from target audiences (patients, family members and caregivers, mental health professionals, journalists and media professionals, educators, members of the clergy) integrate action groups and help design strategies for action.

- Work in cooperation with other organizations and institutions and contribute for the construction of a coalition movement around mental health issues.

- Develop sustainability through partnership with the public, private, and nonprofit sectors.

During the year 2002 the project expanded actions initiated in 
the previous year and grew to integrate around 30 active volunteer collaborators. Action groups worked in close collaboration to accomplish the initial objectives, generating informational material and the S.O.eSq. webpage (www.soesq.org.br). Outreach activities conducted by the project coordinators and collaborators produced several newspaper and magazine articles on schizophrenia and the S.O.eSq. Project. Partnership with UNIFESP (São Paulo Federal University) and CEDRHU (Centro de Desenvolvimento de Recursos Humanos da Secretaria de Estado da Saúde/Human Resources Center - State Health Department) was established for the Educational workshops carried for relatives/caregivers, patients, mental health professionals and religious leaders. Another important achievement was the foundation, in December 2002, of the Associação Brasileira de familiares, amigos e portadores de Esquizofrenia - ABRE (Brazilian Schizophrenia Association).

These are the first outcomes of a project that aims at establishing a strong network of actions to change the scenario of schizophrenia in Brazil. Evaluation of initial activities is underway and will help planning for the next steps. Moreover, accomplishment of this enterprise will depend on institutional and community support. Responsibility must be shared, for this is an encompassing challenge.

\section{References}

1. World Health Organization. The ICD-10 classification of mental and behavioral disorders. Geneva: World Health Organization; 1993.

2. Sartorius N. One of the last obstacles to better mental health care: the stigma of mental Illness. In: Guimón J, Fisher W, Sartorius N, editors. The image of madness. Basel: Karger; 1999. p. 96-104.

3. Sartorius N. Stigma: what can psychiatrists do about it? The Lancet 1998;352:1058-9.
In conclusion, overcoming stigma associated to schizophrenia requires extensive, sustained and integrated efforts to raise community awareness, change people's attitudes through education, develop and modify public policy and laws to reduce discrimination, increase legal protection and ensure access to treatment of quality for all. This complex task must involve those who experience stigma but seldom are heard - people with schizophrenia and their caregivers - in designing strategies to improve social acceptance and community inclusion. Ultimately, it will be the acceptance and recognition of the authority of those who suffer that will make the difference, raising their dignity and quality of life.

Cecília C Villares

Departament of Psychiatry, Federal University of São

Paulo

Norman Sartorius

University of Geneva
4. Sartorius N. Editorials. Iatrogenic stigma of mental illness. BMJ 2002;324(7352):1470-1.

5. Jorge M. Mental health priorities in Brazil. Psychiatry on-line Brazil [serial online] 1997;(2). Available from: URL: http://www.polbr.med.br/arquivo/menalmgi.htm

6. Leitão RJ, Ferraz MB, Mari JJ. A prevalence based cost of illness study of schizophrenia in São Paulo State, Brazil. Schizophr Res 2002;53(3):259. 